\title{
EDITORIAL
}

\section{Avoid being Prey to Predatory: The Publishing Dilemma}

'Publish or perish', the old adage is more germane than ever before as academicians nowadays are under constant pressure for the demand of number of publications, a causal element for their promotions, tenure, and funding. As a result, authors may wish for quick publications, when traditional publishing is known to be slow, subjective to some extent and may be less interested in one's work. This milieu coupled with the shift from print to online publications, created an unprecedented opportunity for predatory publishers to appear and establish, luring the young and inexperienced or those who anticipate merit with little effort.

\section{Predatory publishing is an}

exploitative academic publishing business that deceive authors to publishing with fraudulent journals. These journals neither check the quality, legitimacy, integrity, or reliability of the article nor they provide the editorial or other services. Authors who publish in these journals, inadvertently harm their carrier being subjected to criticism afterwards and without any recognition/citation for their work. Eventually these publications defile the academic literature and the funds/grants utilized are wasted. A majority of these debatable journals are from low- and middleincome countries and authors from the same are at high risk of being victims.

Although difficult to differentiate from original publishers, there are typical characteristics of predatory publishing. The authors receive unsolicited email correspondence from these journals with flattering or poor language inviting for article submission. The correspondence often makes contradictory claims such as 'You need to submit within a week' and then stating, 'You may submit whenever it is convenient for you'. They always promise speedy publication implying the lack of proper peer-review process. Generally, these journals request a handling/processing fee at the time of submission in place of a publication fee. Some predatory journals offer attractive discounts on this fee.

Other characteristics of predatory publishing include, journal titles or websites mimicking original journals, or without a website of professional quality and editorial boards with unknown persons or all editors from a single institution. Typically, the authors' colleagues are not aware about such journals. The predatory journals or the publishers are neither listed in bibliographic databases nor indexed in scholarly databases such as ScienceDirect, Web of Science or PubMed. The papers published are of poor quality with meaningless results and with recurring typographical and factual errors. Additionally, the papers published in a single journal may have widely different focuses and may be of outside the journals' scope. Predatory journals also claim unrealistically high impact despite having recent commencement. They do not describe copyright agreements or strategies to manage misconduct or conflicts of interests. 
To curtail the damage caused by predatory publishing, Jeffrey Beall, a librarian and assistant professor at the University of Colorado, created a list of potentially rogue journals and publishers (available at https://beallslist.net/) and updates it yearly. Unfortunately, the predatory publishing business continues to grow, evidently shown by the Beall's list and other similar lists. To avoid being easy prey for these journals, one can search for lists of established open access journals, such as the Directory of Open Access Journals (available at https://www.doaj.org/). However, some journals may not be catalogued in either whitelists or blacklists or that the journal is incorrectly classified in the wrong list. Therefore, the authors with manuscripts of their scholarly work need to carefully navigate open access or subscription journals before deciding to submit.

With the awake of COVID-19 pandemic, a high volume of papers and preprints are being published even in ranked and indexed journals in a matter of days. The senior scholarly authors, editors and reviewers are vested with the responsibility to ensure that the core value of 'peer reviewed' in academic publishing is not jeopardized and the scientific validity, trustworthiness, and ultimately the public health are not challenged in these instances.

I believe, a change in publishing business is imperative to curb the publishing dilemma. Essentially, authors need to take informed decisions as to where they submit their valuable work.

\section{THINK ! CHECK $\checkmark$ SUBMIT >}

Dr. Varuni Tennakoon (MBBS, MPhil, PhD), Department of Anatomy, Faculty of Medical Sciences, University of Sri Jayewardenepura.

E-mail: varuni@sjp.ac.lk 